\title{
Asintomatic Giant B1 Thymoma: A Case Report
}

\section{Hernán Oliu Lambert ${ }^{1 *}$ | Natalia Altagracia De la Cruz de Oliu $^{2}$ | Ariana Mariel Cabrera Grisanty ${ }^{3}$ | Naly Cruz Ventura ${ }^{4}$}

*Correspondence: Hernán Oliu Lambert

Address: ${ }^{1}$ General surgeon, Thoracic Surgeon and Master on Thoracic Oncology, Instituto Oncológico Regional del Cibao, Santiago de los Caballeros, Dominican Republic; ${ }^{2}$ General Surgeon, Master Executive on Hospital Management, Master on Investigación, Instituto Oncológico Regional del Cibao, Dominican Republic; ${ }^{3}$ Pathologist, Instituto Oncológico Regional del Cibao, Dominican Republic; ${ }^{4}$ Oncologist and Radiotherapy, Instituto Oncológico Regional del Cibao, Dominican Republic e-mail $\bowtie$ : dr.oliu@outlook.com

Received: 18 January 2021; Accepted: 25 January 2021

Copyright: (C) 2021 Oliu Lambert H. This is an open-access article distributed under the terms of the Creative Commons Attribution License, which permits unrestricted use, distribution, and reproduction in any medium, provided that the original work is properly cited.

\section{ABSTRACT}

Introduction: Thymoma is the most frequent tumor of the anterior mediastinum. Surgical resection is the best treatment and has been considered the most important determinant of long-term survival.

Clinical case: A 31-year-old male patient is presented with the diagnosis of a mediastinal tumor by chest tomography, who underwent a thymectomy, finding a giant tumor that was completely removed. Microscopic analysis completed a B1 thymoma.

Conclusions: Low grade thymomas are usually easy to remove and have low complication rates with a good prognosis. Keywords: Thymoma, Thymectomy, Thymus Neoplasms

\section{Introduction}

The thymus is an organ of the lymphatic and endocrine system located in the lower part of the neck and upper part of the anterior mediastinum, between the lungs and behind the sternum. It has a clear influence on the development and maturation of the lymphatic system and on the defense-immune response of our body (immunocompetent $\mathrm{T}$ lymphocytes are produced in the thymus, even in people of mature age in whom the thymus has atrophied). As an organ of the endocrine system, it secretes hormones and other soluble factors, which in addition to controlling the production and maturation of $\mathrm{T}$ lymphocytes, regulates the activity and interactions of $\mathrm{T}$ cells in peripheral tissues. It can also influence the development of sex glands (Lacoba Girón, 2010).

The thymoma is the most common tumor of the anterior mediastinum, but it is a relatively minor disease. Recent studies have reported an estimated incidence of 0.15 per 100,000 person-years in the United States (Engels and Pfeiffer, 2003). Surgical resection is the best available treatment and has been 
considered the most important determinant of long-term survival (Masaoka et al., 1981; Kondo and Monden, 2003). In this review we present the case of a young patient with a giant thymoma with a favorable evolution.

\section{Case Presentation}

We present a 31-year-old male patient with an apparent history of good health who came to the emergency consult complaining about acute chest pain of mild intensity, constant, with irradiation to the left shoulder and arm, stabbing, which was relieved with non-steroidal anti-inflammatory analgesics, and was not associated to other symptoms. Nothing to report on physical examination. Several studies were carried out to make the diagnosis, including a contrasted chest tomography where a mass with regular borders in the upper mediastinum could be seen that reached the antero-inferior mediastinum, an aspiration biopsy of the mass was performed and reported a thymic tumor with the presence of Hassall's corpuscles. The preoperative evaluation and preparation was carried out and he was taken to the operating room. The patient was asintomatic until the day of consult.

A median sternotomy access was performed, finding a large thymus tumor with loose adhesions to the pericardium, the left pulmonary hilum and the upper and lower lingular segments of the left lung. The adhesions were carefully released, ligating the thymic veins. A firm adherence to the left innominate vein was found, adherent thymus segment was resected along with involved segment of innominatevein and vascular suture was performed. The left phrenic nerve was disected as it was part of the tumor. It was possible to extract the complete tumor and the wound was closed in layers. The patient evolved favorably and after 5 days hospitalized he was discharged (Fig. 1 and Fig. 2).

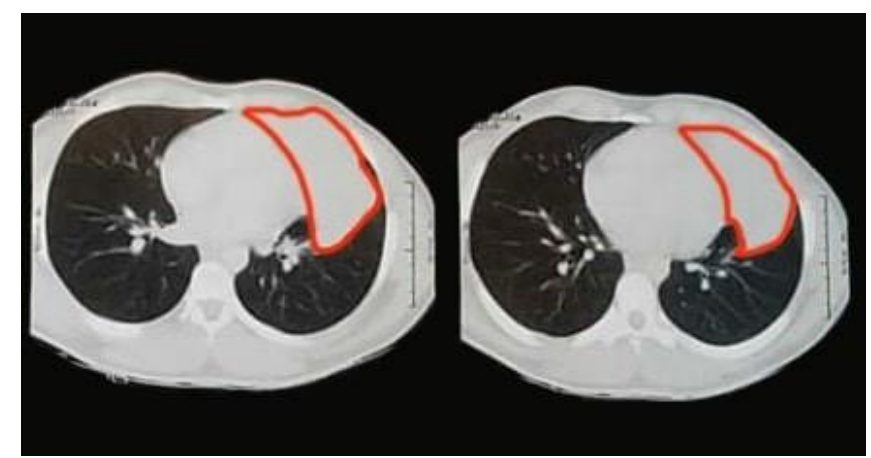

Figure 1: Two axial preoperative tomographic sections are shown, where the tumor of the thymus is seen delimited by the red line

A 16 x $13 \times 5.5 \mathrm{~cm}$ specimen weighing 468 grams was delivered to the pathology department. Microscopic analysis observed a multinodular proliferation of small or medium-sized lymphoid cells with scant cytoplasm and rounded or lobed nuclei, with small nuclei, there are no areas of necrosis and no follicular cells are observed, among the lymphoid population large rounded cells and epithelioid in 
appearance with amphophilic cytoplasm and large vesicular nuclei with frequent eosinophilic macronucleolus. Rosettes or perivascular spaces are not identified, focally cell differentiation is observed. Hassall corpuscles were not identified (Fig. 3).

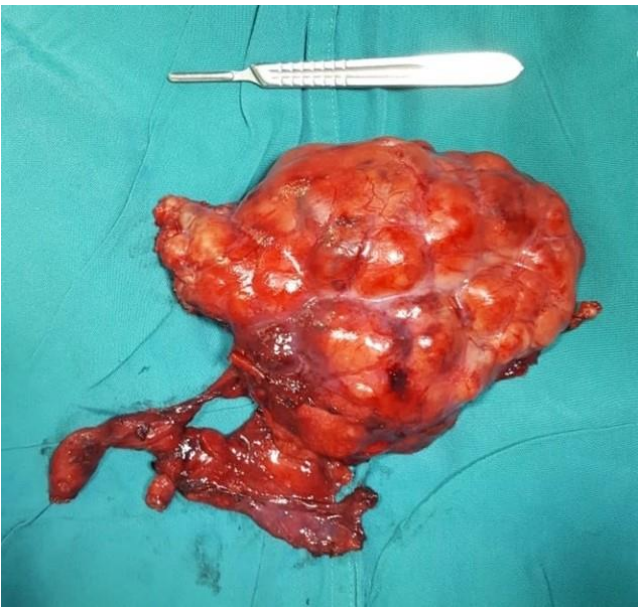

Figure 2: Macroscopic view of the removed thymus showing the complete " $\mathrm{H}$ " structure, with a dependent tumor of the left lobe with an apparently normal right lobe

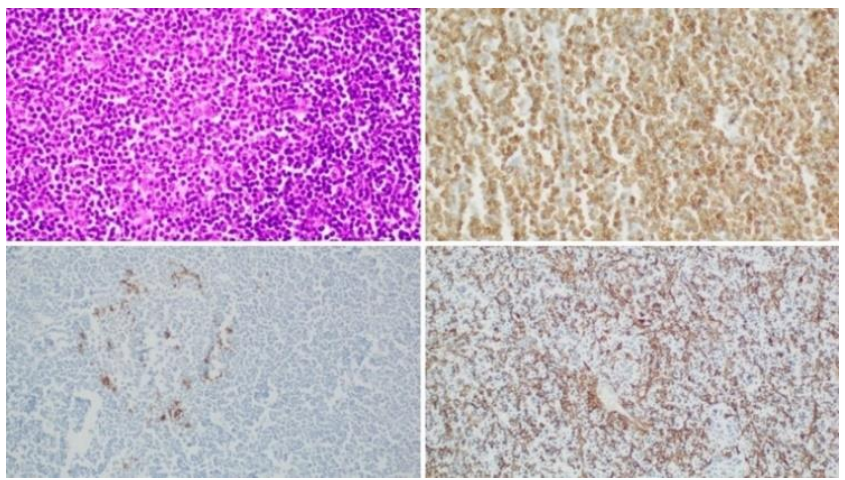

Figure 3: Shown from left to right above the $\mathrm{H} / \mathrm{E}$ staining where the tumor population can be seen, following the intensely positive CD3 immunohistochemical stains in all lymphocytes, then pankeratin that only marks the epithelial cells in the background and fin ally CD1A positive as well in lymphocytes

The immunohistochemistry performed resulted in:

- $\quad$ CD3 positive in all lymphocytes.

- CD20 negative in all lymphocytes.

- bcl2 positive in $30 \%$ of lymphocytes.

- Positive pankeratin in all background epithelial cells.

- CD1A negative in all lymphocytes.

Concluding as a Thymoma B1 according to the classification of the World Health Organization (Travis et al., 2015). 
It was discussed in the thoracic surgery multidisciplinary group and it was decided to keep the patient under observation without any other treatment.

\section{Discussion}

Thymomas constitute approximately 47\% of all mediastinal tumors in adults (Azuma et al., 2018). About a half of these cases are asymptomatic, and are discovered incidentally by routine radiography or at autopsy (Sachiko et al., 1993).

The classifications of thymomas have varied over the years. Being the most used, the one already stated by the World Health Organization and that of Masaoka modified by Koga in 1994 (Koga et al., 1994). In our center we used the first one, for which the tumor was classified as a B1 thymoma. Thymomas of this type are rich in lymphocytes, and their differentiation from type B2 tends to be difficult at times, one of their distinctive features being the presence of medullary islets and the absence of epithelial cell clusters5. These thymomas are considered low risk (Ruggeri et al., 2016).

The surgery of this entity has varied from the transcervical access performed by Sauerbruch in 1911 (Sauerbruch, 1913) to the uniportal resection technique performed by Francesco Paolo Caroni, et al. (2015). Thymectomy performed for thymoma through a sternotomy, which is the classic approach, has long been considered the most effective method of treatment, despite the severe postoperative pain and the longer recovery period due to the degree of functional impairment and the greater need for postoperative assisted ventilation in patients with symptoms of respiratory distress and in those who have suffered myasthenia gravis for a long period of time (Triviño et al., 2015). However, it turns out to be an optimal technique that allows visualizing the entire field of work and accessing all anatomical compartments of the mediastinum effectively.

There is a trend to perform thymectomies using minimally invasive methods due to the advantages over open ones in the recovery of patients, being the uniportal technique one of the most used at present. The subxiphoid method has gained popularity and is very useful for accessing the anterior mediastinum. However, these new techniques seem not to be suitable for giant tumors, especially for tumors larger than $10 \mathrm{~cm}$ (Gonzalez-Rivas et al., 2017), like this case.

\section{Conclusions}

Giant thymomas are rare and sometimes asymptomatic and can develop silently at times; surgery turns out to be his immediate method of solution. Low-grade thymomas are usually easy to remove and have low complication rates with a good prognosis. 


\section{References}

Azuma Y, Otsuka H, Makino T, Koezuka S, Anami Y, Sadamoto S, Wakayama M, Tochigi N, Shibuya K, Iyoda A. Giant thymoma successfully resected via median sternotomy and anterolateral thoracotomy: a case report. Journal of Cardiothoracic Surgery 2018; 13: 26.

Caronia FP, Fiorelli A, Santini M, Cottone S. Uniportal bilateral video-assisted thoracoscopic extended thymectomy for myasthenia gravis: a case report. J Thorac Cardiovasc Surg 2015; 150: e1-e3.

Engels EA and Pfeiffer RM. Malignant thymoma in the United States: Demographic patterns in incidence and associations with subsequent malignancies. Int J Cancer 2003; 105: 546-551.

Gonzalez-Rivas D, Wu CF, de la Torre M. Uniportal video-assisted thoracoscopic thymectomy and resection of a giant thymoma in a patient witness of Jehova. J Thorac Dis 2017; 9: E556-E559.

Koga K, Matsuno Y, Noguchi M, Mukai K, Asamura H, Goya T, Shimosato Y. A review of 79 thymomas: modification of staging system and reappraisal of conventional division into invasive and non-invasive thymoma. Pathol Int 1994; 44: 359 -367.

Kondo K and Monden Y. Therapy for thymic epithelial tumors: A clinical study of 1,320 patients from Japan. Ann Thorac Surg 2003; 76: 878-884.

Lacoba Girón V. Las enfermedades del timo. FMC - Formación Médica Continuada En Atención Primaria. 2010; 17: 512517.

Masaoka A, Monden Y, Nakahara K, Tanioka T. Follow-up study of thymomas with special reference to their clinical stages. Cancer 1981; 48: 2485-2492.

Ruggeri MR, Demarchi G, De Lauro J, Lucilli N. Resección extendida por timoma gigante de mediastino. Informe de caso y re-visión bibliográfica. Rev Argent Cirug 2016; 108: 77-78.

Sachiko F, Tomio Y, Rieko M, Kohji M, Keisuke I, ShigekiN. Intracaval and Intracardiac Extension of Malignant Thymoma. Internal Medicine 1993; 32: 257-260.

Sauerbruch F. Thymektomie bei einem Fall von Morbus Basedowimit Myasthenia. Mitteilungenaus den Grenzgebieten der Medizin und Chirurgie. 1913; 25: 746.

Travis WD, Brambilla E, Burke AP, Marx A, Nicholson AG. WHO Classification of Tumours of the Lung, Pleura, Thymus and Heart. Journal of Thoracic Oncology 2015; 10: 1240-1242.

Triviño A, Congregado M, Loscertales J, Cozar F, Pinos N, Carmona P, Jiménez-Merchán R, Girón-Arjona JC. Análisis comparativo del abordaje para el tratamiento del timoma estadio I-II: VATS versus abordaje convencional. Cirugía Española 2015; 93: 466-471. 